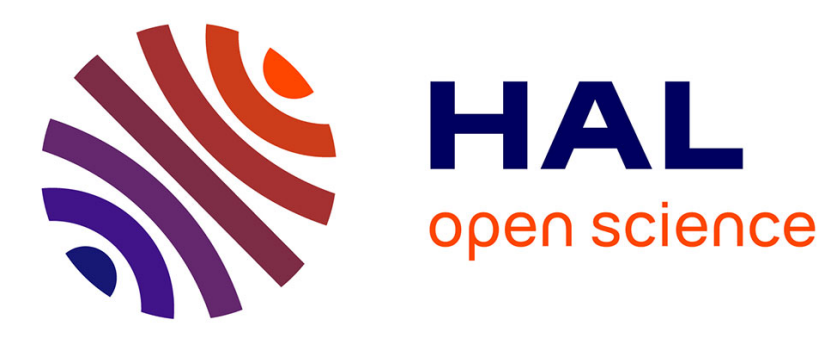

\title{
A minimal sense of here-ness
}

Frédérique de Vignemont

\section{To cite this version:}

Frédérique de Vignemont. A minimal sense of here-ness. Journal of Philosophy, 2021, 118 (4), pp.169187. 10.5840/jphil2021118413. ijn_03508201

\section{HAL Id: ijn_03508201 https://hal.science/ijn_03508201}

Submitted on 3 Jan 2022

HAL is a multi-disciplinary open access archive for the deposit and dissemination of scientific research documents, whether they are published or not. The documents may come from teaching and research institutions in France or abroad, or from public or private research centers.
L'archive ouverte pluridisciplinaire HAL, est destinée au dépôt et à la diffusion de documents scientifiques de niveau recherche, publiés ou non, émanant des établissements d'enseignement et de recherche français ou étrangers, des laboratoires publics ou privés. 


\section{A minimal sense of here-ness}

Frédérique de Vignemont

Institut Jean Nicod

CNRS - EHESS - ENS - PSL University

29 rue d'Ulm 75005 Paris

Email : frederique.de.vignemont@ens.fr

Abstract: In this paper, I give an account of a hitherto neglected kind of 'here', which does not work as an intentional indexical. Instead, it automatically refers to the immediate perceptual environment of the subject's body, which is known as peripersonal space. In between the self and the external world, there is something like a buffer zone, a place in which objects and events have a unique immediate significance for the subject because they may soon be in contact with her. I argue that seeing objects as being here in a minimal sense means seeing them in the place in which the perceptual system expects the world and the body to collide. I further argue that this minimal notion of here-content gives rise to a tactile sense of presence. It provides a unique experiential access to the reality of the seen object by making us aware of its ability to have an effect on us. 
How do we experience the location of objects that we perceive? In almost all languages, one can find a linguistic distinction between 'here' and 'there' (Levinson, 2004). ${ }^{1}$ Whereas 'here' is a marker of proximity, which normally refers to a region that includes the speaker (where I am), 'there' normally refers to what is farther away, a distal region more remote from the speaker (where I am not). Imagine, for instance, that you are standing in the middle of the jungle admiring a rare colourful bird up on a tree and remaining perfectly still to avoid scaring it. A natural way to describe the situation is to say that you see the bird as being 'up there', on its branch. Suddenly you catch a glimpse of a snake crawling towards your foot. There is a sense in which the snake looks to you to be 'just right here'. You then experience its spatial proximity, but also its immediate significance for you, for your well-being and for what you should do to protect yourself.

The boundary at which 'here' stops and 'there' starts is usually conceived as being fixed by the speaker's intentions (Perry, 2001). ${ }^{2}$ There is no actual limit to the spatial extension of 'here'. You could think, for instance, that the bird is very rare 'here' (meaning in Brazil). In this paper, I will give an account of a hitherto neglected kind of 'here', which does not work as an intentional indexical. Instead, it automatically refers to the immediate perceptual environment of the subject's body, which is known as peripersonal space. Since the eighties, numerous studies have found that the processing of the immediate surrounding of one's body displays highly specific multisensory and motor features, distinct from those that characterize the processing of far space. In between the self and the external world, there is something like a buffer zone, a place in which objects and events have a unique immediate significance for the subject because they may soon be in contact with her, whether she wants it or not. I shall argue that seeing objects as being here in a minimal sense means seeing them in the place in which the perceptual system expects the world and the body to collide. I will further argue that this minimal notion of here-content gives rise to a tactile sense of presence. 


\section{Here $_{0}$}

Putting aside anaphoric uses and deviant causal chains due to technology (such as an answering machine), 'here' normally refers to the region of space in which the subject is located. The question is whether the subject needs to be able to represent her location qua her own for her to represent objects and events as being here. More broadly speaking, which degree of selfrepresentation does the minimal here-content require? According to Christopher Peacocke (2014), we can distinguish among three degrees of self-representation ${ }^{3}$ :

- Degree 0: The subject cannot represent anything as standing in relation to herself. She does not have any de se content.

- Degree 1: The subject can have mental states that represent objects and events as standing in relations to herself but she does not have the use of the first-person concept. She can only have non-conceptual de se content.

- Degree 2: The subject has the use of the first-person concept. She can have conceptual de se content.

Evans (1982, p. 153) notes: "It is true that $<\mathrm{p}=$ here $>$ is the same thought as $<\mathrm{I}$ am at $\mathrm{p}>$; but this does not mean that I identify here as where I am". ${ }^{4}$ Peacocke (2014) goes a step further and claims that there can be a here-notion in the complete absence of self-notion. Consequently, creatures at degree 0 of self-representation, which have no self-referential abilities whatsoever, are able to generate a map of the world around themselves, and refer to locations on this map by using the notion of here. They identify 'here' to the vantage point from which they perceive the world but they are not able to represent $<$ I am here $>$ and place where they are on a mental map. One may say that they can have de hinc content, but not de se content (Schellenberg, $2016)^{5}:$ 
None of its perceptual states have de se contents of such forms as that thing is that direction from me. Rather, they have here-contents, such as that thing is that direction from here (...) Its map has, so to say, not a de se pointer I am here, but rather one saying this place on the map is here. (Peacocke, 2014, p. 30)

From now on, I shall refer to this minimal notion of here at degree zero of self-representation as 'here 0 '. It does not entail that here $e_{0}$ is only available to creatures at degree 0 . Having selfreferential abilities does not preclude one to have here $_{0}$-content. The notion of here only states that it does not require being able to use the first-person, neither at the non-conceptual, nor at the conceptual level. Because it is cognitively minimal, the notion of here ${ }_{0}$ should thus be largely found throughout the animal kingdom, from insects to humans. It displays the same core features as any here-notion, though in a selfless way. More precisely, I propose that it fulfills the following two criteria: (i) here ${ }_{0}$ is spatially anchored and centred on the subject, and (ii) here $_{0}$ has a special cognitive significance.

First, any here-content must be connected to a particular spatiotemporal object in such a way that variations in the object's spatial properties should produce variations in the here-content. Here-content can then refer to a particular location in virtue of the object being at that location. Now for here 0 -content, the hypothesis is that it is not anchored to self-location. What then gives it its location? To follow up on Evans $(1982,153)$, how does one identify 'here, ' if one does not identify 'here, ${ }_{0}$ as where one is? I propose for reasons that will become clearer with time that instead of self-location, it is sufficient for here 0 to be anchored on body location. Here ${ }_{0}$ refers to the location of the subject's body. However, even this primitive definition may still be too sophisticated. It indeed implies that the creature is able to represent the various segments of its body as belonging to a unified whole. One may then propose a fragmented notion of here 0 , which refers to the places in which the various parts of the body are. This bodily definition of one's location in space involves no self-notion and appears to be the most cognitively minimal. 
What, then, allows the perceptual system to individuate the right body parts to anchor the

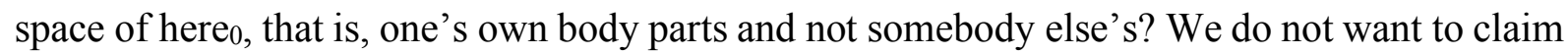
that one needs to be first aware of which body is one's own in order for one to be able to determine which space should be represented as here ${ }_{0}$. Such an answer would indeed bring back the first-person (the space of here ${ }_{0}$ is the space anchored on one's body qua one's own). Instead, we can propose that the perceptual system exploits the same mechanism than the one that allows the motor system to act with the right body. To reach for a cup of tea, the motor system uses information about the bodily effector that is relevant, in that case, the hand in connection with the arm and the shoulder. There is no need to represent the bodily effector qua one's own. All that is needed is to represent its posture, size, and flexibility in a format directly exploitable by the motor system to plan and guide the movement. This type of information is represented in what is known as the body schema. The body schema represents bodily parameters that are useful for action planning and control in a sensorimotor format. One can interpret the notion of body schema in light of Millikan's (1995) notion of pushmi-pullyu representation (hereafter PPR) (Vignemont, 2018). ${ }^{6}$ PPR is governed both by truth and activity guidance. Its content varies as a direct function of a certain variation in some body part and it directly guides behaviour using this body part. What is interesting is that there is no need to translate descriptive information into directive information. Nor is there any need for the descriptive content to be de se to motivate the subsequent behaviour. It possibly represents "this hand", but not "my hand". This hand is my own but I do not need to represent it as my own at the sensorimotor level. One can then propose that the body schema is used to anchor here ${ }_{0}$. The space that is perceived as being here is $_{\text {in }}$ the space that surrounds the body parts as they are represented in the body schema.

However, one may wonder whether one can get rid of the first-person so easily (Taylor, 1964; Schwenkler, 2014). ${ }^{7}$ More precisely, can the sense of here ${ }_{0}$ have a special cognitive 
significance if it is centred on the body instead of the self? Perry (1990) asks us to compare the following two scenarios:

a) You see that it is raining but you do not know where you are, you only know that it is raining here.

b) You believe that it is raining in Grand Island but you do not know that it is the city you are in.

In the scenario (a), your belief is sufficient to motivate you to take an umbrella. The spatial indexical 'here' has a distinctive cognitive significance, similar to the significance of the firstperson. It is because you know that the fact that it is raining is relevant for you that you act in the appropriate way. One might then conclude that without a self-notion, a here-notion would lose its cognitive significance. The body, which anchors here 0 , has indeed not the same cognitive significance as the first-person. Consider Kaplan's (1989) famous example: I see in a window the reflection of a man whose trousers appear to be on fire. ${ }^{8}$ It is only if I believe 'My trousers are on fire' that I feel directly motivated to do something about it. A content of the type 'The trousers on those legs are on fire', on the other hand, seems disconnected from action and

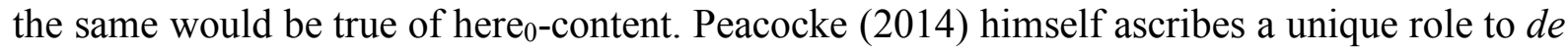
se content for action. He claims that creatures at degree zero can display physiological changes (such as change of colour or release of chemicals), but no bodily movements:

The case as described does sever any tight connection between the presence of spatial content in perception and spatial bodily action by the creature. (Peacocke, 2014, 31)

If we take Peacocke to his words, then here ${ }_{0}$ would have little cognitive significance. Then seeing a snake as being here ${ }_{0}$ and seeing the snake next to the tree without knowing that it is where you are located would have the same impact on you. But if the notion of here 0 is so disconnected from action, one may wonder in what sense it still qualifies as a here-notion. 
One strategy to block this objection consists in questioning the special cognitive significance of the first-person indexical (Cappelen and Dever, 2013; Millikan, 1990). ${ }^{9}$ One can conceive that one forms the intention that a certain state of affairs obtain, for instance, that a certain door is closed, and that triggers the action without the need to appeal to any self-referential attitude, such as a de se intention of the type 'I walk to the door and turn my hand'. In this debate, I believe that it is especially interesting to note that all animals, some of which being possibly creatures at degree zero of self-representation, display protective behaviours. It seems hardly likely that they do so by representing threats as being dangerous to them even at the nonconceptual level. Nor is their defensive response limited to the release of chemicals, as speculated by Peacocke (2014, p. 30). For instance, insects, such as fruit flies, can display flight responses triggered by the detection of looming visual stimuli that are influenced by the size of the stimulus (Tammero and Dickinson 2002).${ }^{10}$ Furthermore, they have an internal model of their limb segments that is used by their motor system, which is close to what we call body schema in mammals (Dürr and Schilling, 2018). However, insects seem hardly to qualify for Peacocke's (2014) degree 1, which, according to him, requires the ascription of agency. It thus follows that there are situations in which action does not require de se content. In response to Schellenberg (2016) who criticizes Peacocke for ascribing so few abilities to creatures at degree 0, Peacocke (2016, p. 352) himself later acknowledges that he was maybe "too timid" in his early characterization of what creatures at degree 0 could do and that they can do far more than what he originally thought. ${ }^{11}$

To recapitulate, one does not need to represent "danger next to me" or "danger next to my foot" for one to withdraw one's foot. It is sufficient to represent "danger here 0 ", where here is anchored in the body schema, to trigger the appropriate response. The notion of here 0 that concerns me in this paper is thus cognitively significant. ${ }^{12}$ 


\section{How far beyond the body?}

In the previous section, I argued that the notion of here $_{0}$ is conceptually coherent. It is spatially centred on the subject's body parts and it can explain some of the subject's behaviours. However, a full grasp of here 0 involves a grasp not only of its spatial anchoring, but also of its spatial extension. If we accept that one can perceive objects in the environment to be 'here, such as a snake in the jungle, the spatial extension of here ${ }_{0}$ must go beyond the bodily location of the subject that perceives the world. But how far beyond? When does the threat stop being

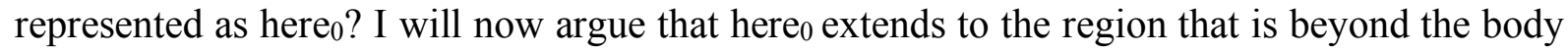
but that is still represented within a bodily frame of reference. This region is known in the literature as peripersonal space, which corresponds to the immediate surrounding of what one takes to be one's body (up to $30-50 \mathrm{~cm}$ ). But beforehand, we need to rule out two alternative notions of here.

On one interpretation, only the subject can be here. The extent of 'here' is restricted to the zero point from which we see the world, or, as Schellenberg $(2016$, p. 339) puts it, to the "vantage point from which one is currently perceiving and from which one would act in relation to objects were one to act". On this interpretation, we experience all objects as being "out there", no matter their distance from us (Eilan, McCarthy and Brewer, 1993). ${ }^{13}$ When in the jungle, not only the bird but also the snake is represented as being 'there'. Richardson (2017), for instance, describes her perceptual surrounding as follows:

For example, when I look at my pencil it seems to be there, where there is a place distinct from the place-here-from which I am aware of it. This here-there distinction constitutes sight's perspectival spatial character. (Richardson, 2017)

On the contrary, according to a radically different interpretation, we can describe the objects that we see as here although they are far from us. Not only can the snake be represented as here, but also the bird up in the tree. For instance, you might say to your friend next to you: 'Look, 
the bird is here!'. By 'here', you then refer to the region of the jungle, in which you are located. As mentioned in the introduction, a standard conception of 'here' is in terms of intentional indexicality: the extent of the region that it refers to depends on the speaker's communicative intentions and the interlocutor needs additional information to understand what it refers to (Perry, 2001).

The objective of this paper is not to deny the legitimacy of these two here-notions but rather to highlight the existence of a further here-notion, which can refer to surrounding objects and events but whose spatial extension is not fixed by the subject's intentions. Instead it is fixed by the perception of peripersonal space. It was the neuroscientist Rizzolatti and his collaborators (1981) that first found evidence that the brain encodes in a special way the immediate surrounding of the body, which they called "peripersonal space". They discovered neurons in the ventral premotor areas in monkeys normally activated by tactile stimuli on the body, but also by visual stimuli if they were presented in the space close to the body. Since then, and especially these last ten years, many experimental studies have reported the multisensory and motor peculiarities of this zone (Vignemont et al., forthcoming). ${ }^{14}$ Objects in peripersonal space are not yet in contact with the body, but they may soon be, and this contact may be welcome (when grasping an object), or not (when colliding into an obstacle). The existence of what may be conceived as a buffer zone allows us to be ready and well prepared. This, I will

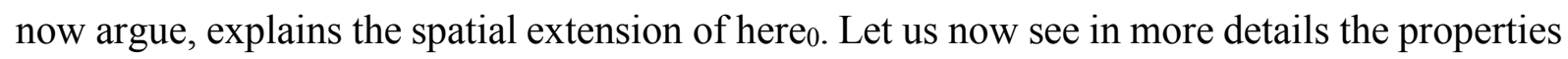
of peripersonal space.

\subsection{A bodily frame of reference}

I can see objects on my left or in front of me, in egocentric coordinates. Although the axes on which the egocentric location is computed use body parts, such as the eyes, the head and the torso, the egocentric location remains in the space external to the body. Now, when the objects 
are located in peripersonal space, they are not only encoded in an egocentric frame of reference; they are also encoded in a bodily frame of reference. What is close to one's body can be soon in contact with it, either because the close-by object moves or because one moves. Consequently, the perceptual system predicts that the location of objects that are for now only close to the body will soon be on the skin itself. Michael Graziano (2018), one of the leading experts on peripersonal space in neuroscience, thus qualifies peripersonal space as a "second skin". Less metaphorically, peripersonal vision (visual processing of peripersonal space) exploits the same frame of reference as touch and pain. Bodily experiences are felt to be located in what we may call somatotopic coordinates (also called skin-based coordinates). For instance, I feel touch on my hand, on my foot, or on my head. Likewise, I can see objects in my perihand, in my peri-foot, or in my peri-head. To illustrate the difference between the somatotopic and the egocentric frames, consider the following example. There is a rock next to my right foot (somatotopic coordinates) on my right (egocentric coordinates). I then cross my legs. In external space, the egocentric coordinates have not changed (I still see the rock on my right) but the rock is now close to my left foot, and the somatotopic coordinates have changed.

In order to be prepared for objects to get in contact with one part or another of the body, the perceptual system forms tactile expectations, but this is so only when objects are located in peripersonal space, and not when they are farther away. There is a range of visuo-tactile effects that occur only when the visual stimulus is presented in the immediate surrounding of the body. Consider the syndrome of tactile extinction. Patients with tactile extinction can correctly detect touch on their left hand, unless they are simultaneously touched on their right hand. Then they report feeling nothing on their left hand. What is interesting is that a similar extinction occurs if the patients merely see a visual stimulus close to their right hand (Ladavas et al., 1998). Visuo-tactile extinction can be explained by the fact that the perceptual system anticipates the potential impact of what is seen, thus generating tactile expectations on the right hand, which 
then competes with the experience of the actual tactile stimulus on the left hand. In healthy participants, it has also been shown that one is slower and makes more mistakes to judge the location of tactile stimuli if at the same time one sees a visual stimulus close to the body but at a location that is incongruent with the tactile loci (Spence et al., 2004). Interaction of this type does not occur when visual stimuli are presented further away.

Peripersonal perception thus constantly anticipates that external events that are close-by can soon become bodily events. The notion of tactile expectation gives a concrete way to operationalize the notion of here . Here $_{0}$ refers to the place that the body parts occupy. The place that the body parts occupy is the place in which whatever happens there is expected to happen on the body. This is well illustrated by the rubber hand illusion. It has now come to the attention of philosophers that one can induce the illusory experience that a rubber hand is one's own hand (Botvinick and Cohen, 1998). ${ }^{15}$ What is less well known is that the illusion works only if the rubber hand is located within peripersonal space. There is not a slow linear decrease of the illusion with the separation increasing between the real hand and the rubber hand. Instead, there is a drop in the illusion when the rubber hand is positioned beyond the boundaries of peripersonal space (Lloyd, 2007). Put it another way, it is only when the rubber hand is perceived as being here 0 that it can be experienced as a part of one's body.

\subsection{Ready for impact}

We just saw that objects that are still located beyond the body boundaries can be anticipated to be soon in bodily space. But why anticipating? One could provide a purely perceptual reason: impact prediction enables enhanced sensory processing of the anticipated event (Clery et al., 2015). Proof of sensory improvement can be found in a series of studies that compare detection and discrimination of stimuli presented in peripersonal space and in far space. For instance, participants are better in discriminating the shape of the objects that are presented next to their 
body (Blini et al., 2018). This facilitation effect cannot be explained by differences in apparent size: the objects presented in far space are made to look the same size as the objects presented in close space. This can neither be explained by attentional facilitation. If whatever is close were given attentional priority just because it is close, then one should be better in every perceptual task, and this is not the case. For instance, participants are slower at localizing a target among distractors when the visual display is close compared to when it is far (Abrams et al., 2008). One can explain this result in evolutionary terms. Perception must be especially thorough in peripersonal space because partial overlook can be dangerous. What is close can indeed be a threat. Hence, one can afford not looking at all the objects for a faraway visual scene but one needs to watch closely where one puts one's hand or one's foot.

This brings us to the defensive function of peripersonal perception. From an evolutionary viewpoint, if peripersonal space is encoded in a special way, it is to detect immediate threats and to elicit protective behaviours as quickly as possible if necessary (Graziano, 2009). Now one may reply that if the threat is so close to the body, then it is already too late. There is, however, a trade-off between the cost of anticipating collision and the gain of being ready to quickly react. It seems that it is only when the impact probability is high that the organism directly connects perception to action. When the threat is farther away, there are still many possible outcomes and the probability of danger remains low. Compare the following two scenarios. You see a snake 10 meters away or just next to your foot. In the first case, there are still many options that you can consider before deciding what to do - and if you fail to notice the snake, it does not necessarily put your life in danger because the snake can go to another direction. By contrast, there is no time left for deliberation when the snake is next to you - and missing it can directly endanger you. With spatial proximity comes temporal proximity, which gives rise to specific constraints on the relationship between perception and action. To anticipate the snake attacking is to be able to react more quickly. 
Since its discovery, peripersonal space has actually been ascribed a motor function (Rizzolatti et al., 1997, Brozzoli et al., 2012, Bufacchi and Iannetti, 2018). ${ }^{16}$ Still, one should note that objects in peripersonal space are represented in a specific way no matter whether we plan to act on them or not. What matters for the perceptual system is not that we actively move (or intend to move), but more simply that the distance with objects in the environment can change, and this change can also result from the surrounding objects moving. The fact is that peripersonal processing is especially sensitive to dynamic stimuli, some neurons responding more than twice as much to stimuli in movement relative to the subject (Colby et al., 1993), and the extent of peripersonal space depending on the velocity of approaching stimuli (Fogassi et al., 1996). Peripersonal processing evolved precisely to take into account the dynamic properties of the surrounding world. Now, when one is actually moving, the movement unfolds within peripersonal space (even if the goal is far beyond). Hence, peripersonal perception cannot afford to be detached from the motor system. What is seen in one's immediate surrounding must be able to directly connect with what one does, and vice-versa. This direct connection to action is made possible by the fact that peripersonal space is mainly represented in brain regions that are dedicated to action guidance (in the premotor areas and in the ventral section of the intraparietal sulcus).

The space of here $e_{0}$ is thus a space in which perception directly connects with action. Like the body schema that anchors it, its representation can be interpreted as a pushmi-pullyu representation. There is thus no need for inferential structure for the descriptive content to have a relation to action, nor is there any need to represent the self. Roughly speaking, peripersonal content represents "danger here", which suffices to both describe the fact that there is a closeby threat and to make one act. As such, it affords great economy in terms of response time and cognitive effort. 


\subsection{A fraction of behavioural space}

The notion of here $e_{0}$ that I have developed is made available to us by perception and it is made possible by our dispositions to act on the immediate surrounding of our body. This bears some similarities with Evans's (1982) notion of "behavioural space". On his view, the egocentric content of perceptual experiences is explained by one's dispositions to act: "having spatially significant perceptual information consists at least partly in being disposed to do various things". (Evans, 1982, 155). The behavioural space can be defined as a complex network of connections with behavioural outputs, which can involve many different types of movements, with different types of body parts, and performed in different ways. These connections are shared across all sensory modalities: there is a unique behavioural space no matter the sensory access one has to it (Evans, 1985). ${ }^{17}$ The egocentric content does not represent this multiplicity of dispositions. It is only made possible by them (Briscoe, 2014).

Although the view that I defend shares many aspects with Evans's view and with his followers (Briscoe, 2009), we do not have the same explanandum. The behavioural space is relatively large. Evans wants to account for the egocentric content of all perceptual experiences, no matter whether what one sees is in the subject's proximity or farther away. All that matters is that one can be connected with the object by dispositions to direct one's actions towards it (including the mere action of turning one's head towards it). It includes all that you can directly perceive from an egocentric point of view, the snake, the bird, and even the moon that you see above the trees. The spatial distance between the subject and what is seen is not relevant. Thus, Evans's dispositional theory does not aim to account for the distinction between 'here' and 'there'. By contrast, I focus only on a small part of this behavioural space. My objective is not to account for all our egocentric experiences. It is simply to delineate within these experiences a specific class of visual experiences that present the seen objects as being here . $_{\text {. In our original }}$ example, only the snake is seen as here 0 , but not the bird, and even less the moon. 
A further difference with Evans's notion can be highlighted by appealing to the objection of the sentient statue. How does a statue that can perceive but that cannot move experience space? According to Evans, it would not be able to represent objects egocentrically: "When there is no possibility of action and perception, 'here'-thoughts cannot get a grip" (Evans, 1982, 153). Likewise, one can argue that the sentient statue cannot perceive the world as being here ${ }_{0}$. It would not make sense for peripersonal processing to evolve in a creature that cannot actively move. What is the point of being ready if you are powerless? Anticipating forthcoming events is useful only if one can prepare one's reactions to them. Thus, ultimately the multisensory readiness that characterizes peripersonal perception can be explained by the need for motor readiness. So far both behavioural space and peripersonal space show the same type of dependency to action.

The difference arises if one slightly modifies the thought experiment and imagines a creature normally endowed with self-movements but that can no longer move. Evans would probably reply like Schellenberg (2007) and claim that it suffices for this creature that at one point it had the capacity to move for it to see the world egocentrically. But the same is not true for here $0^{-}$ content. It has been shown that after only 10 hours of immobilization of the right arm, participants show a contraction of the peripersonal space surrounding their arm (Bassolino et al. 2015). One may thus legitimately wonder what would happen after a longer immobilization. One classically contrasts performance with competence but it is important to make a further distinction within competence itself. On the one hand, there is what we may call motor expertise, which can be defined as a long-term bodily know-how based on a history of successful actions (for example, I know how to ride a bicycle). On the other hand, there is the practical knowledge of one's 'here and now' bodily capacities (I can no longer cycle with my broken leg). Unlike egocentric content, here 0 -content depends on the here-and-now bodily competence, and not on motor expertise. Arguably, the subjects in the immobilization 
experiment have retained their long-term motor expertise but they have lost their physical ability to exploit it. Peripersonal space is anchored in what one can do now, in the actual capacities that are represented in the body schema. The body schema is a highly malleable representation that keeps track of the types of movements that the body can actually perform at each moment. It is constantly updated and if the body schema is altered, then peripersonal processing is altered too, as illustrated by the immobilization study, and also by the case of tool use. One can act on farther objects with a tool than without. This increased motor ability leads to a modification of perceptual processing of the objects that are next to the tool, which has been incorporated in the body schema. After tool use, these objects are processed as being peripersonal (Cardinali et al 2009; Farnè and Ladavas, 2000). One might then say that one sees objects close to the tip of the tool as here but only when one is using it, and not before. What is interesting is how quickly the space of here ${ }_{0}$ is modified. Once one drops the tool, one regains

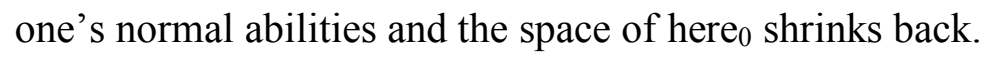

To recapitulate, there are specific computational principles that characterize the perception of peripersonal space, which differ from those that govern the perception of far space. These principles are determined by the predictive function of peripersonal perception, which can be ultimately explained by the need to act and react. It is because one has the disposition to act on one's immediate environment that one needs to perceive it in a specific way. Dispositions for actions directed at one's immediate surroundings make possible peripersonal content. This is not to say that peripersonal content represents these dispositions. To borrow Briscoe's (2014) words, it is only a claim about the conditions under which a visual experience will have peripersonal content, and thus here ${ }_{0}$-content.

\section{The tactile sense of presence}




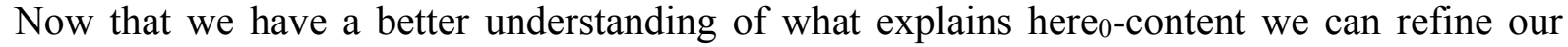
characterization of this special type of spatial awareness. As a first rough approximation, one may say that seeing the snake next to your foot as being here is being aware of its presence, its scary presence you might even say. If you were looking at the painting of the snake, you would normally not feel the snake itself as being present, only the painting. The sense of presence typically characterizes the kind of visual awareness that one has in real life seeing, when one is 'face to face' with the object, but that is lacking when seeing an object that is depicted in a picture (Noë, 2005; Matthen, 2005, 2010; Dokic, 2010, 2012, 2018; Ferretti, 2018; Kind, 2018). ${ }^{18}$ On most accounts of the sense of presence, however, there is no spatial limit to where one can experience it. In other words, you see the snake here ${ }_{0}$ as present but you also see the bird over there as present. Matthen (2010) claims that the sense of presence is anchored in nearspace (which, on his view, reaches up to 10 feet away, thus, farther than peripersonal space), but he also argues that it extends to far away objects that are connected to near objects by visible paths. This notion of the sense of presence thus seems too broad to characterize what is unique

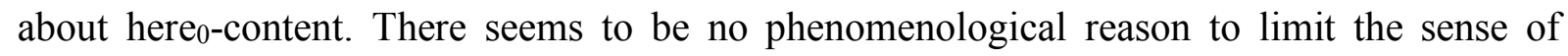
presence - interpreted as a generic notion - to one's immediate surrounding. However, I will now argue that there is more than one type of presence, one of them being specific to here $0^{-}$ content. More precisely, in real-life seeing I propose that we have a visual sense of presence for all the objects for which we have a direct visual access, but that we have also a tactile sense of presence for the objects that we see as being located here . $_{\text {. }}$

Discussions on the sense of presence have focused almost exclusively on the visual modality. ${ }^{19}$ The most frequent interpretation is in terms of reality. When one is aware of a tree that one sees as being present, one is normally aware of this tree as being located in a mindindependent world, a world that exists independently of mental episodes directed towards it and in which one is also located. By contrast, when seeing the painting of the tree, we are normally 
aware that there is no real tree (unless in trompe l'oeil). Touch is even more susceptible than vision to give an experiential access to reality. The way we talk actually reflects that advantage, as reflected in our use of "tangible" as a synonym for "real". Consider also the example of the apostle saint John who needed to touch Jesus's body back from the dead to be aware of his presence among the livings: "Except I shall see in his hands the print of the nails, and put my finger into the print of the nails, and thrust my hand into his side, I will not believe" (20: 25). For some, touch is actually the primary sense because it is the only one to give us a sense of the reality of what we perceive (Armstrong, 1962; Condillac, 1754; James, 1880; Maine de Biran, 1812). ${ }^{20}$ More specifically, touch is the only sensory modality that presents the perceived objects as being causally efficient (Massin and Vignemont, 2020). It informs us that the felt object can move, or have an effect, on other entities. When one actively touches an object, one exerts a force on it and one feels not only one's effort but also its resistance to one's effort: "There is no commoner remark than this, that resistance to our muscular effort is the only sense which makes us aware of a reality independent from ourselves" (James, 1880). Only effortful touch presents us with the contrast between ourselves as striving agents and an independent causally empowered being that resists our effort. It does not only present us with there being something beyond us; neither does it only present with there being something causally empowered. It presents us with both, at once. Tactile experiences thus provide us an experiential access to the reality of the touched object by making us aware of the ability of the object to move or to have an effect on us (Armstrong, 1997). This, I propose, is the tactile sense of presence.

The hypothesis is that this tactile sense of presence can be elicited not only by touch, but also by peripersonal vision: when I see the snake as being here 0 , I am tactually aware of its presence. This does not entail that I literally feel touch. I am not aware of any pressure exerted by the seen object on my skin. As we saw in the previous section, seeing objects close to one's 
body parts triggers tactile expectations but one should not confuse tactile expectations with tactile sensations and when the object is in the immediate surroundings of the body, though not in contact with it, only the former occurs. Nonetheless, tactile expectations can generate a tactile sense of presence.

The hypothesis that perceptual expectations are responsible for the sense of presence has already been defended for visual awareness (Noë, 2005; Siegel, 2010). The objective then was to account for the fact that one can be visually aware of things that one does not see. For instance, one can be visually aware of a whole mug as being present, although one receives no visual inputs from the back hidden from sight. This is so, it has been argued, in virtue of one having some visual expectations about one's view and how it would change were one to change one's perspective on the mug. However, this hypothesis has been criticized (Dokic, 2012, 2018; Kind, 2018). One reason is that there are situations in which we form these expectations and yet do not experience presence. Another reason concerns the notion of perceptual expectation itself. According to Alva Noë and Susanna Siegel, they should be conceived as the perceptual awareness of counterfactual truths but one may wonder such counterfactual truths can actually be visually experienced. However, the view that I defend for the tactile sense of presence does not fall under the same type of criticisms because it does not appeal to the same notion of perceptual expectation. One way to conceive of tactile expectation, as occurring in peripersonal processing, is in terms of probabilistic distribution: there is a high probability that the seen object gets in contact with the skin. Roughly speaking, tactile expectation does not tell us that one will experience the pressure of the object on the skin if the distance between the object and the body is reduced to zero; it simply tells us that it is very likely that one will experience the pressure of the object. Like an occurring tactile sensation, the high probability of tactile sensation can provide a tactile sense of presence. Tactile expectation gives to the subject the 
same experiential access to the reality of the object as actual touch, though there is no on-line tactile stimulation.

Consider the following examples. You are seated alone on a long empty bench in a waiting room and a perfect stranger comes to sit just next to you. There is a distance at which her proximity makes you feel uncomfortable (known as personal distance, cf. Hall, 1966). ${ }^{21}$ One way to interpret this effect is that your perceptual system anticipates this perfect stranger touching you and you experience this social contact as being unwelcome, or even repulsive. Likewise, when I see the snake next to my foot, my tactile system anticipates its contact and this expectation generates a tactile sense of the presence of the snake. Put it another way, when I see the snake as here 0 , I am aware not only of the snake as being located in a mind-independent world (visual sense of presence), but also of the causal efficiency of the snake, of its ability to act on me (tactile sense of presence). By contrast, when I see the bird up there, I am only aware of the bird as being located in a mind-independent world (visual sense of presence). I am not aware of its causal efficiency.

I have thus defended the view that we are visually aware of the world as being present, no matter where we look at, but we are also tactually aware of what is in the close surroundings of our body as being present. The tactile sense of presence that accompanies peripersonal perception best characterizes the sense of here ${ }_{0}$. It asserts both the proximity of the seen object to the body and its causal efficiency. It is precisely because one is aware that what one sees could have an effect on oneself that one needs to be prepared to react to it.

\section{Conclusion}

Seeing objects as being here 0 then simply means seeing them as being in peripersonal space, in the place in which the perceptual system expects the world and the various parts of the body 
to collide. Here $_{0}$-content is relatively primitive, based on direct connection between perception and action and devoid of first-personal content. Still it has a major assertive force. It expresses that what is seen close-by is present, not only in the sense that it is spatially connected to one part of our body, but also in the sense that it can act on one's body part, and possibly even hurt

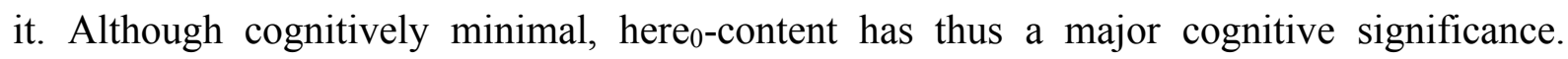
Arguably, it is one of the fundamental building blocks on which the degree 1 of selfrepresentation can emerge but more work is needed to understand the role that the minimal here $_{0}$-content plays in our cognitive architecture.

Acknowledgment: I am greatly indebted to Robert Briscoe, Mohan Matthen, and John Schwenkler for their continuing support and insightful comments on this paper. This work was funded by the ANR-17-EURE-0017 FrontCog and the ANR-10-IDEX-0001-02 PSL.

\footnotetext{
${ }^{1}$ Steve Levinson, “Deixis”. In L.R. Horn and G. Ward (eds), The handbook of pragmatics (pp. 97-121). Blackwell, 2004.
}

2 John Perry, Reference and reflexivity. Stanford: CSLI, 2001. See also Perry, J., "SelfNotions". Logos 11: 17-31, 1990.

${ }^{3}$ Christopher Peacocke, The Mirror of the World: Subjects, Consciousness, and SelfConsciousness. Oxford: Oxford University Press., 2014 See also Peacocke, C., "The Nature and Role of First and Second Person Content”. Analysis, 76(3): 345-353, 2016.

${ }^{4}$ Gareth Evans, The Varieties of Reference. New York: Oxford University Press, 1982.

${ }^{5}$ Susanna Schellenberg, "De se content and de hinc content". Analysis, 76(3), 334-345, 2016. See also Schellenberg, S., “Action and self-location in perception”. Mind 116: 603-631, 2007. 
${ }^{6}$ Ruth Millikan, "Pushmi-pullyu representations". Philosophical perspectives, 9, 185-200, 1995. Frédérique de Vignemont. Mind the body: An exploration of bodily self-awareness. Oxford: Oxford University Press, 2018.

7 John Schwenkler, "Vision, Self-Location, and the Phenomenology of the "Point of View". Noûs, 48(1), 137-155, 2014. Charles Taylor, The Explanation of Behaviour. London: Routledge, 2014.

${ }^{8}$ David Kaplan, “Demonstratives", in J. Almog, J. Perry, and H. Wettstein (eds), Themes from Kaplan. Oxford: Oxford University Press, pp. 481-563, 1989.

${ }^{9}$ Ruth Millikan, “The myth of the essential indexical”. Noûs, 723-734, 1990. Herman Cappelen, \& Josh Dever, The inessential indexical: On the philosophical insignificance of perspective and the first person. Oxford: Oxford University Press, 2013.

${ }^{10}$ On defensive behaviour in insects, see Tammero, L. F., \& Dickinson, M. H., "Collisionavoidance and landing responses are mediated by separate pathways in the fruit fly, Drosophila melanogaster". Journal of Experimental Biology, 205(18), 2785-2798, 2002. On peripersonal space and body schema in insects, see Dürr, V. and Schilling, M., "Transfer of spatial contact information among limbs and the notion of peripersonal space in insects." Frontiers in Computational Neuroscience 12, 101, 2018.

${ }^{11}$ Alternatively, one may argue that Peacocke's taxonomy of degrees of self-representation is not fine-grained enough. For instance, Eilan (2016) and Neander (2016) propose an intermediate level, a degree 0.5 of self-representation. Naomi Eilan, "You Me and the World". Analysis, 76(3): 311-324, 2016. Karen Neander, "Peacocke on primitive self-representation." Analysis, 76(3), 324-334, 2016.

12 This is not to say that it has exactly the same cognitive significance as when one has selfreferential abilities. 
${ }^{13}$ Naomi Eilan, Rosaleen McCarthy, and Bill Brewer, "General introduction”. In Eilan, McCarthy, and Brewer, eds., Spatial Representation: Problems in Philosophy and Psychology, New York: Oxford University Press, 1-22, 1993. See also Louise Richardson, "Sight and the body", in Frédérique de Vignemont and Adrian Alsmith (eds), The Subject's Matter: Selfconsciousness and the Body. Cambridge Mass.: the MIT Press, 2017.

${ }^{14}$ For full discussion on peripersonal space, see Frédérique de Vignemont, Hong Yu Wong, Andrea Serino, Alessandro Farnè (eds). The world at our fingertips: a multidisciplinary investigation of Peripersonal space. Oxford: Oxford University Press. 2021. Here is also a list of key studies. R.A Abrams et al., "Altered vision near the hands". Cognition, 107(3), 10351047, 2008. M. Bassolino et al., "Dissociating effect of upper limb non-use and overuse on space and body representations". Neuropsychologia, 70, 385-92, 2015. E. Blini et al., "Mind the Depth: visual perception of shapes is better in peripersonal space". Psychological Science, 29(11), 18681877, 2018. C. Brozzoli et al., "Peripersonal space: a multisensory interface for body-object interactions". In M. M. Murray and M. T. Wallace (eds). The Neural Bases of Multisensory Processes. Boca Raton, FL: CRC Press, 2012. Bufacchi, R. J., \& Iannetti, G. D., “An Action Field Theory of Peripersonal Space”. Trends in cognitive sciences, 22 (212), 2018. L. Cardinali et al., "Tool-use induces morphological updating of the body schema". Current biology, 19(12), R478-R479, 2009. C.L. Colby et al., "Ventral intraparietal area of the macaque: anatomic location and visual response properties". J. Neurophysiol. 69, 902-914, 1993. Farnè, A., and Làdavas, E., "Dynamic size-change of hand peripersonal space following tool use". Neuroreport, 11(8), 1645-1649, 2000. L. Fogassi et al., “Coding of peripersonal space in inferior premotor cortex (area F4)". Journal of neurophysiology, 76(1), 141-157, 1986. Graziano, M.S., The Spaces Between Us. A Story of Neuroscience, Evolution, and Human Nature. Oxford: Oxford University Press, 2018. E. Làdavas et al., "Neuropsychological evidence of an integrated visuotactile representation of peripersonal space in humans". Journal 
of Cognitive Neuroscience, 10(5), 581-589, 1998. Reed, C. L., Grubb, J. D., \& Steele, C., "Hands up: attentional prioritization of space near the hand". Journal of Experimental Psychology: Human Perception and Performance, 32(1), 166, 2006. G. Rizzolatti et al., "Afferent properties of periarcuate neurons in macaque monkeys. II. Visual responses". Behavioural Brain Research, 2(2), 147-63, 1981. G. Rizzolatti et al., "The space around us". Science, 277(5323), 190-1, 1997. Spence, C., Pavani, F., and Driver, J., "Spatial constraints on visual-tactile cross-modal distractor congruency effects". Cognitive, Affective, and Behavioral Neuroscience, 4(2), 148-69, 2004.

${ }^{15}$ Participants look at a rubber hand visually presented in front of them with their own arm hidden behind a screen. The rubber and the biological hands are touched in synchrony or asynchrony. Participants then report that they feel touch on the rubber hand and that it seems as if the rubber hand were their hand. For more details, see Botvinick, M. and Cohen, J., “Rubber hands 'feel' touch that eyes see”. Nature, 391, 756, 1998. Lloyd, D. M., "Spatial limits on referred touch to an alien limb may reflect boundaries of visuo-tactile peripersonal space surrounding the hand". Brain and Cognition, 64(1): 104-9, 2007.

${ }^{16}$ Although they are sometimes confused, it is important to distinguish peripersonal space from what is sometimes called in the literature "reaching space". Peripersonal space has a different functional role: it is not only about reaching and grasping, but it also includes protective movements such as withdrawal. Consequently, it is not centred only on the hand, arm and shoulder, but also surrounds the head, the torso and the legs.

${ }^{17}$ Molyneux famously asked whether a person born blind might immediately identify a shape previously familiar to them only by touch if they were made to see. Evans replies positively: both vision and touch can be understood using the same behavioural code; thus, the perception of the shape is the same for touch and for vision and the blind person that has regained sight can recognize the visually presented object. See Gareth Evans, "Molyneux's Question”. In his 
Collected Papers. Oxford: Oxford University Press, 1985. For a detailed discussion of Evans, see Robert Briscoe, "Egocentric spatial representation in action and perception". Philosophy and Phenomenological Research, 79(2), 423-460, 2009. See also Briscoe, R., "Spatial content and motoric significance". AVANT. Pismo Awangardy Filozoficzno-Naukowej, (2), 199-217, 2014.

${ }^{18}$ On the sense of presence, see Jérôme Dokic, "Perceptual Recognition and the Feeling of Presence," in B. Nanay (ed.), Perceiving the World. Oxford University Press., 2010 See also Dokic, J., "Pictures in the flesh: Presence and appearance in pictorial experience". British Journal of Aesthetics, 52(4), 391-405, 2012. Dokic, J., "Visual Awareness and Visual Appearances: A Dual View", in Phenomenal presence, edited by Fabian Dorsch and Fiona McPherson, Oxford: Oxford University Press, 2018. Amy Kind, "Imaginative Presence", in Phenomenal presence, edited by Fabian Dorsch and Fiona McPherson, Oxford: Oxford University Press, 2018. Gabriele Ferretti, "Visual feeling of presence". Pacific Philosophical Quarterly, 99, 112-136, 2018. Mohan Matthen, Seeing, Doing and Knowing: A Philosophical Theory of Sense Perception. Oxford: Oxford University Press, 2005. Matthen, M., "Two visual systems and the feeling of presence”. In N. Gangopadhyay, M. Madary, \& F. Spicer (Eds.), Perception, action, and consciousness: sensorimotor dynamics and two visual systems, Oxford: Oxford University Press, 107-24. 2010. Alva Noë, A., "Real presence". Philosophical Topics, 33, 235-364, 2005. Susanna Siegel, The Contents of Visual Experience. New York: Oxford University Press, 2010.

${ }^{19}$ Jérôme Dokic (2012, p. 400) acknowledges that presence can be found in other modalities, taking the example of hearing thunder, in which you are aware of the thunder as being present. ${ }^{20}$ This means only that touch gives us the appearance of reality, and not reality itself. Objects of our tactile perception are presented to us as existing independently from us. It does not tell us whether they do exist independently from us. On touch and the sense of reality, see David 
Armstrong, A world of states of affairs. Cambridge, Cambridge University Press, 1997. Etienne Bonnot de Condillac, Traité des sensations, traité sur les animaux. Paris, Fayard, 1754/1997. William James, "The feeling of effort”. Anniversary Memoirs of the Boston Society of Natural History, 1880. Maine de Biran, F. P. G., Essai sur les fondements de la psychologie, Paris, Vrin, 1981. Olivier Massin and Frédérique de Vignemont, "Unless I put my hand into his side, I will not believe". In The Epistemology of Non-Visual Perception, edited by Dimitria Gatzia \& Berit Broogard, Oxford University Press, pp. 165-187, 2020.

${ }^{21}$ Hall, E.T., The hidden dimension. New York: Doubleday \& Co, 1966. 